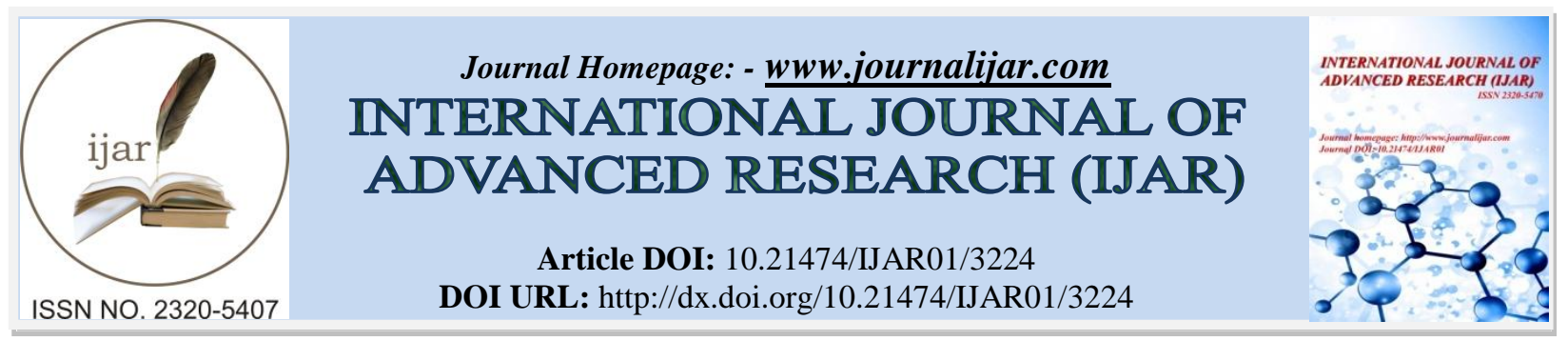

RESEARCH ARTICLE

\title{
SPECTROPHOTOMETRIC CHARACTERIZATION OF RUTHENIUM(II) POLYPYRIDYL COMPLEXES WITH PARA QUINONES IN AQUEOUS MEDIUM.
}

T. Sumitha Celin and G. Allen Gnana Raj*

Department of Chemistry \& Research Centre, Scott Christian College (Autonomous), Nagercoil,Tamilnadu, India.

\section{Manuscript Info}

Manuscript History

Received: 14 December 2016

Final Accepted: 14 January 2017

Published: February 2017

Key words:-

quinones, binding, Benesi Hildebrand

Plot,UV/Vis spectroscopy.

\begin{abstract}
Two Ruthenium(II)) polypyridyl complexes $\left[\mathrm{Ru}(\mathrm{NN})_{3}\right]^{2+}[(\mathrm{NN}) \rightarrow$ bpy, dmbpy] were synthesised. The binding interaction of these ruthenium complexes with para quinones have been studied by absorption spectral technique. These metal complexes have the absorption maximum in the range of $448-458 \mathrm{~nm}$. They have the emission maximum in the range 590-610 nm. The binding constant $\left(\mathrm{k}_{\mathrm{b}}\right)$ for these complexes are determined from the Benesi-Hildebrand equation using the absorption intensity data. Structural effect plays an important role in the binding of the quinones with the complexes.
\end{abstract}

Copy Right, IJAR, 2017,. All rights reserved.

\section{Introduction:-}

Quinones are ubiquitous in nature. p-quinones are important molecules in biological electron transport. They act as electron acceptor in photosynthesis [1-3]. They are well known for their citotoxicity. They have very high toxicological and pharmacological effects. They are used as anticancer drugs. They have antiviral, antifungal properties. Quinones have the capacity to accept electrons and are easy to protonate. They form stable hydrogen bonds. Due to their high mobility and small size, they have the property to get reduced. In order to understand the electron transfer properties of quinones, several photosensitizers have been designed. Inter and intra molecular electro transfer reactions have been studied.Their properties can be changed on complexation with proteins [4]. Transition metal complexes have received a considerable amount of attention over the past three decades [5-7]. Of these, particularly ruthenium (II) polypyridyl complexes have received much attention due to its tunable photophysical and photochemical properties. These complexes have a potential application in the field of photochemistry and biochemistry [8-10]. Recently reports show the advantages of ruthenium complexes in the field of cellular imaging and act as anticancer agents [11-14]. They act as good photocatalysts, particularly in the splitting of water molecule into $\mathrm{O}_{2}$ and $\mathrm{H}_{2}$, used in dye sensitized solar cells and used in photodynamic therapy. We present here a comprehensive study of interaction of ruthenium polypyridyl complexes with quinones in aqueous medium by using UV/Vis spectrophotometric parameters.

\section{Experimental methods:}

\section{Materials:-}

The ruthenium polypyridyl complexes $\left[\mathrm{Ru}(\mathrm{NN})_{3}\right]^{2+}$, where $\mathrm{NN}=$ 2,2-bipyridine (bpy) and 4,4'-dimethyl- 2,2'bibyridine (dmbpy) were prepared by reacting $\mathrm{RuCl}_{3} \cdot 3 \mathrm{H}_{2} \mathrm{O}$ with the corresponding ligands according to the known procedures $[15,16]$. The ligands and quinones used for this present work were procured from Sigma Aldrich. Binding studies were carried out using double distilled water.All experiments were carried out at room temperature.

Corresponding Author:- T. Sumitha Celin.

Address:- Department of Chemistry \& Research Centre, Scott Christian College (Autonomous), Nagercoil, Tamilnadu, India. 


\section{Spectroscopic Measurements:-}

The absorption spectral measurements were carried out using SYSTRONICS 2203 Double beam Spectrophotometer. Emission intensity measurements were carried out using JASCO FP 8600 spectrofluorometer. The structure of the quinones used in the present study was shown in fig 1.<smiles>O=C1C=CC(=O)C=C1</smiles>

(a)

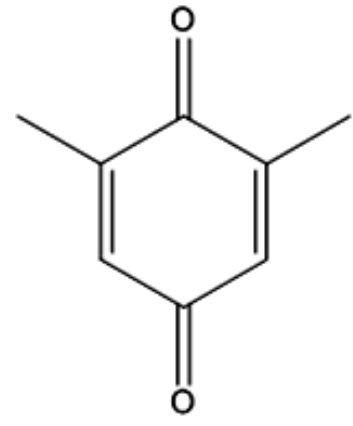

(b)<smiles>COC1=CC(=O)C(OC)=CC1=O</smiles>

(c)
Figure 1. Structure of Quenchers; (b) 2,6-dimethyl-1,4- benzoquinone (a) 1,4-benzoquinone

(c) 2,5-dimethoxy -1,4-benzoquinone.

The binding of $\left[\mathrm{Ru}(\mathrm{NN})_{3}\right]^{2+}$ with various concentrations $\left(4 \times 10^{-6}-2.8 \times 10^{-7} \mathrm{M}\right)$ of quinones have been studied by absorption spectral techniques. The binding constant $\left(\mathrm{k}_{\mathrm{b}}\right)$ of the $\left[\mathrm{Ru}(\mathrm{NN})_{3}\right]^{2+}$ complexes with quinones were determined from Benesi-Hildebrand equation [16] using absorption intensity data [17].

$1 / \Delta \mathrm{A}=1 / \mathrm{K}_{\mathrm{b}} \Delta \varepsilon[\mathrm{H}]+1 / \Delta \varepsilon[\mathrm{Q}]$

Where $\Delta \mathrm{A}$ is the change in the absorption of the complex with various concentrations of [Q] of the quinones. The plot of $1 / \Delta \mathrm{A}$ versus $1 /[\mathrm{Q}]$ gives a straight line and the binding constant $\mathrm{k}_{\mathrm{b}}$ is calculated from the ratio of $\mathrm{y}$ intercept to the slope of the straight line.

\section{Results and discussion:-}

The absorption spectrum and emission spectrum of $\left[\mathrm{Ru}(\mathrm{bpy})_{3}\right]^{2+}$ in aqueous medium is shown in fig. 2 . The complex shows a ligand Centred (LC) absorption peak of high energy at $290 \mathrm{~nm}$ which is due to the promotion of electron from $\pi_{\mathrm{L}}$ to $\pi_{\mathrm{L}}$ *and a metal to ligand change transfer (MLCT) peak at $448 \mathrm{~nm}$. The weak shoulder around $320 \mathrm{~nm}$ corresponds to the metal centered $(\mathrm{MC})$ transition from $\mathrm{t}_{2 \mathrm{~g}}$ to $\mathrm{e}_{\mathrm{g}}$. The complex $\left[\mathrm{Ru}(\mathrm{bpy})_{3}\right]^{2+}$ has the emission maximum at $596 \mathrm{~nm}$.

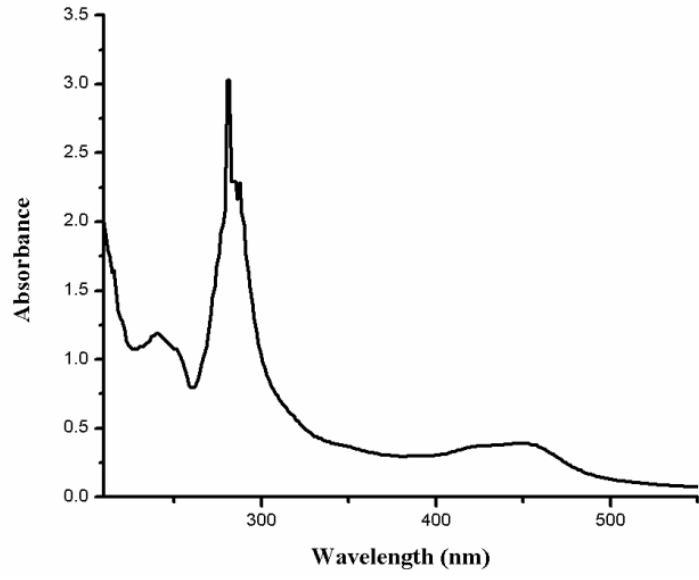

(a)

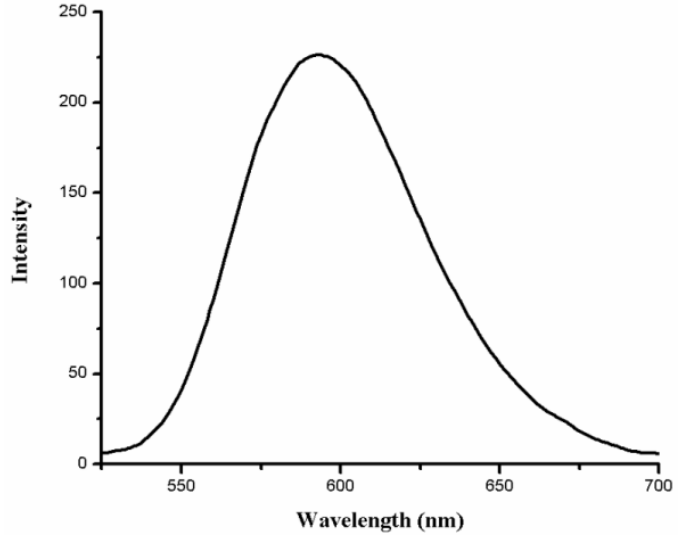

(b)

Figure.2:- (a) Absorption spectrum and (b) Emission spectrum of $\left[\mathrm{Ru}(\mathrm{bpy})_{3}\right]^{2+}$ complex in aqueous medium.

Table 1 gives the photophysical data of the two $\left[\mathrm{Ru}(\mathrm{NN})_{3}\right]^{2+}$ complexes. The red shift in the LC and MLCT transition, on the introduction of methyl group to the parent ligand bipyridine is due to the lowering of the excited state energy. The introduction of dimethyl ligand results in the red shift in the absorption maxima from $448 \mathrm{~nm}$ to 
$458 \mathrm{~nm}$ to the tune of $10 \mathrm{~nm}$, while the emission maxima is red shifted to the tune of 8 nm in homogeneous medium.

Table 1:- Absorption maximum, emission maximum and lifetime of $\left[\mathrm{Ru}(\mathrm{NN})_{3}\right]^{2+}$ in aqueous medium

\begin{tabular}{|l|l|l|l|}
\hline Complex & $\begin{array}{l}\text { Absorption } \\
\text { maximum(nm) }\end{array}$ & Emission maximum(nm) & Lifetime(ns) \\
\hline$\left[\mathrm{Ru}(\mathrm{bpy})_{3}\right]^{2+}$ & 448 & 593 & $* 650$ \\
\hline$\left[\mathrm{Ru}(\mathrm{dmbpy})_{3}\right]^{2+}$ & 458 & 605 & $* 360$ \\
\hline
\end{tabular}

*Data taken from the published report[18]

Electronic absorption spectroscopy is an important technique to explore the interaction of metal complex with pquinones. Inorder to compare the binding strength of the $\left[\mathrm{Ru}(\mathrm{NN})_{3}\right]^{2+}$ complexes with quinones, the intrinsic binding constant $\left(\mathrm{k}_{\mathrm{b}}\right)$ were obtained to monitor the changes in the absorption intensities at $290 \mathrm{~nm}$. The absorption spectra of $\left[\mathrm{Ru}(\mathrm{dmbpy})_{3}\right]^{2+}$ with incremental addition of 1,4-benzoquinone in aqueous medium is shown in fig. 3 .

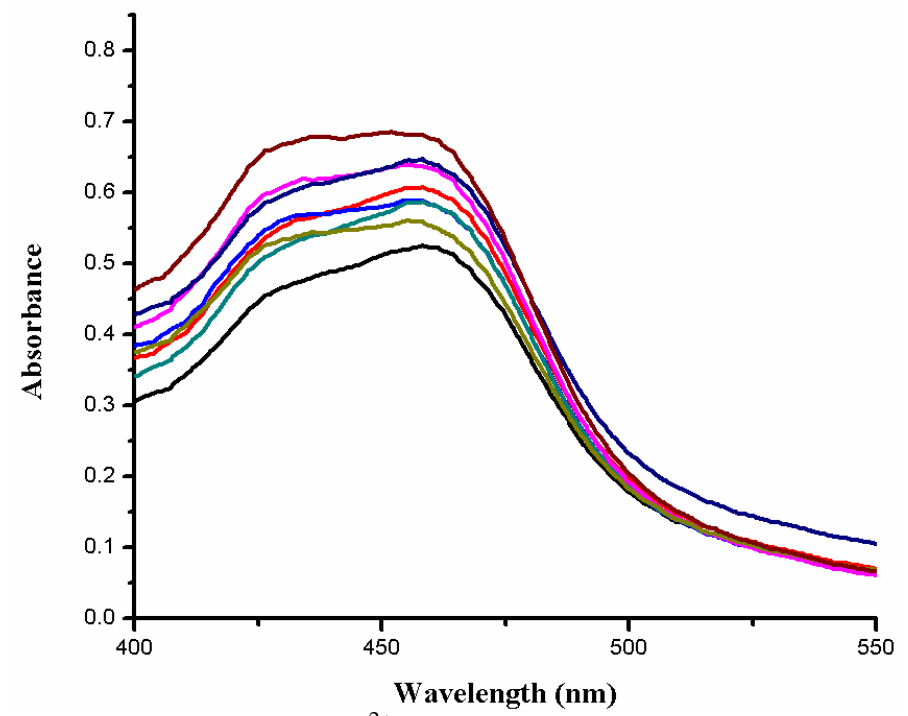

Fig. 3:- Absorption spectrum of $\left[\mathrm{Ru}(\mathrm{dmbpy})_{3}\right]^{2+}$ complex with incremental addition of 2,6-dimethyl $-1,4$ benzoquinone in aqueous medium.

The absorption spectral studies of $\left[\mathrm{Ru}(\mathrm{NN})_{3}\right]^{2+}$ complexes show a steady increase in the LC and MLCT absorption maximum, with incremental addition of 1,4-benzoquinone, 2,6-dimethy-1,4 benzoquinone and 2,5-dimethoxy-1,4benzoquinone. These results indicate the formation of ground state complex. Addition of 1,4-benzoquinone to the $\left[\mathrm{Ru}(\mathrm{bpy})_{3}\right]^{2+}$ complex increases the absorption at $290 \mathrm{~nm}$ and $448 \mathrm{~nm}$, showing the binding of the quinone to the complex. All the quinones show a weak absorption near the MLCT absorption of the complex. So the quinones bind with the LC and MLCT absorption peaks of absorption peaks of $\left[\mathrm{Ru}(\mathrm{NN})_{3}\right]^{2+}$ complex in the ground state [19]. The $\mathrm{k}_{\mathrm{b}}$ values of $\left[\mathrm{Ru}(\mathrm{NN})_{3}\right]^{2+}$ complexes with the quinones 1,4-benzoquinone, 2,6-dimethyl-1,4-benzoquinone and 2,5dimethoxy-1,4-benzoquinone are tabulated in table 2.

Table 2:- Binding constant, $\mathrm{K}_{\mathrm{b}}\left(\mathrm{M}^{-1}\right)$ for 1,4 benzoquinone , 2,6 -dimethyl -1,4 benzoquinone and 2,5-dimethoxy 1,4 benzoquinone with $\left[\mathrm{Ru}(\mathrm{NN})_{3}\right]^{2+}$ complexes in aqueous medium.

\begin{tabular}{|c|c|c|}
\hline \multirow[t]{2}{*}{ Quinones } & {$\left[\operatorname{Ru}(\mathrm{bpy})_{3}\right]^{2+}$} & {$\left[\operatorname{Ru}(\operatorname{dmbpy})_{3}\right]^{2+}$} \\
\hline & \multicolumn{2}{|c|}{$\begin{array}{l}\text { Binding constant } K_{b} \\
\left(M^{-1}\right)\end{array}$} \\
\hline 1,4 benzoquinone & $1.748 \times 10^{4}$ & $2.729 \times 10^{4}$ \\
\hline 2,6 - dimethyl $-1,4$ benzoquinone & $3.138 \times 10^{4}$ & $5.412 \times 10^{4}$ \\
\hline 2,5- dimethoxy $-1,4$ benzoquinone & $3.337 \times 10^{4}$ & $9.754 \times 10^{4}$ \\
\hline
\end{tabular}


The binding constant of $\left[\mathrm{Ru}(\mathrm{bpy})_{3}\right]^{2+}$ complex with 1,4 benzoquinone and 2,6 -dimethyl -1,4 -benzoquinone are $1.748 \times 10^{4}$ and $3.138 \times 10^{4}$ respectively. There is an increase in the intrinsic binding constant value for $\left[\mathrm{Ru}(\mathrm{dmbpy})_{3}\right]^{2+}$ complex of $2.729 \times 10^{4}$ and $5.41 \times 10^{4}$ for the same quinones. The binding constant value for $\left[\mathrm{Ru}(\mathrm{bpy})_{3}\right]^{2+}$ complex with 2,5-dimethoxy -1,4- benzoquinone is $3.337 \times 10^{4}$ and $\left[\mathrm{Ru}(\mathrm{dmbpy})_{3}\right]^{2+}$ complex has a value of $9.754 \times 10^{4}$ for the above said quinone. These datas show that the $\mathrm{K}_{\mathrm{b}}$ values increase on moving from 1,4benzoquinone to 2,5-dimethoxy -1,4- benzoquinone. The value of the binding constant increases when the ligand of the ruthenium complex is changed from bipyridine to dimethyl bipyridine.

Benesi-Hildebrand plot on MLCT absorption of $\left[\mathrm{Ru}(\mathrm{dmbpy})_{3}\right]^{2+}$ complex with incremental addition of 1,4benzoquinone is shown in fig 4 . The plot of $1 / \Delta \mathrm{A}$ versus $1 /\left[\right.$ Quinone] gives a straight line. The binding constant, $\mathrm{k}_{\mathrm{b}}$ of 2,5-dimethoxy - 1,4-benzoquinone with $\left[\mathrm{Ru}(\mathrm{dmbpy})_{3}\right]^{2+}$ complex can be obtained from the ratio of $\mathrm{y}$ intercept to the slope of the straight line.

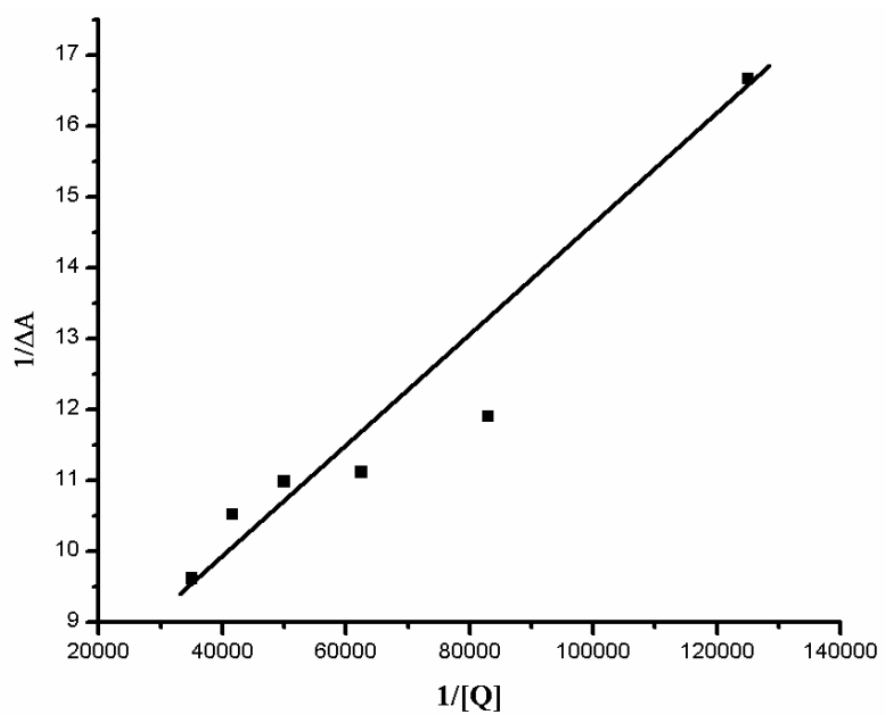

Fig.4. Benesi -Hildebrand plot on MLCT absorption of $\left[\mathrm{Ru}(\mathrm{dmbpy})_{3}\right]^{2+}$ complex with incremental addition of $2,5-$ dimethoxy -1,4- benzoquinone in aqueous medium.

The ground state interaction between the quinones and the bipyridine ring of $\left[\mathrm{Ru}(\mathrm{bpy})_{3}\right]^{2+}$ complexes are hydrophobic and $\pi$-stacking in nature. $\pi-\pi$ stacking interactions exist between the ligands of the Ru(II) complex and the quinones, so the binding also becomes stronger. Binding occurs in the LC and in the MLCT absorption maximum of the complex in the ground state. The $\mathrm{k}_{\mathrm{b}}$ calculated for the quinones shows that, the $\left[\mathrm{Ru}(\mathrm{NN})_{3}\right]^{2+}$ complexes bind strongly to 2,5-dimethoxy -1,4-benzoquinone than that of 2,6-dimethyl-1,4-benzoquinone and 1,4benzoquinone.

\section{Conclusion:-}

In this chapter a comprehensive study was carried out to study the binding interaction of $\left[\mathrm{Ru}(\mathrm{NN})_{3}\right]^{2+} \mathrm{complexes}$ with p-quinones in aqueous medium by using absorption spectral techniques. The binding constants were calculated using Benesi - Hildebrand plot. The experimental results show that the binding of the $\left.\mathrm{Ru}(\mathrm{NN})_{3}\right]^{2+}$ complexes with pquinones depend on the size of the ligand as well as the quinones. Of the two complexes, $\left[\mathrm{Ru}(\mathrm{dmbpy})_{3}\right]^{2+} \mathrm{complex}$ shows the maximum binding interactions with the quinones. The binding of $\left[\mathrm{Ru}(\mathrm{bpy})_{3}\right]^{2+} \mathrm{complex}$ with $2,5-$ dimethoxy -1,4-benzoquinone shows a high value of binding constant $3.337 \times 10^{4}$ which shows that this interaction is stronger than the other two quinones. This may be attributed due to the bulkiness of the quinone. The binding constant of $\left[\mathrm{Ru}(\mathrm{bpy})_{3}\right]^{2+}$ complex with 1,4-benzoquinone is $1.748 \times 10^{4}$ which is the lowest value , which shows the smaller size of 1,4-benzoquinone when compared to the other quinones.

\section{References:-}

1. Comini, L.R., Nunez Montoya, S.C., Samiento. M., Cabrera, J.L., Aruguello, J., Photochem, Photobiol. A, (2007), 188,185.

2. Cape J.L., Bowman, M.K., Kramer D.M.J. Am. Chem. Soc., (2005), 127: 4208. 
3. Colucci, M.A.,Christopher, J.M., Couch, G.A., Org. Biomol. Chem., (2008),6:637.

4. Roura-Perez G., Quiroz, B., Aguilar-Martinez, M., Frontana, C., Solano, A., Gonzalez, I., Bautista-Martinez, J.A., Jimenez-Barbero, J., Cuevas, G., J. Org. Chem., (2007), 72: 1883.

5. Metcalfe, C. and Thomas, J.A., Chem. Soc. Rev., (2003), 32: 215 - 224.

6. Friedman,A.E.,Chambron, J.C., Sauvage, J.P., Turro, N.J. and Barton, J.K., Am.Chem.Soc., (1990), 112: 49604962.

7. Liao, G., Chen, X., Wu. J., Qian, C., Wang, H., Ji, L. and Chao, H., Dalton Trans., (2014), 43: 7811-7819.

8. Gill, M.R. and Thomas, J.A., Chem. Soc. Rev., (2012), 41: 3179-3192.

9. Zhao, Q., Huang, C. and Li, F., Chem. Soc. Rev., (2011), 40: 2508-2524.

10. Elias, B. and Mesmaeker, A.K-D., Coord. Chem. Rev., (2006), 250: 1627-1641.

11. Metcalfe, C. and Thomas, J.A., Chem. Soc. Rev., (2003), 32: 215-224.

12. Bhat, S.S., Kumbhar, A.S., Lonnecke, P. and Hey-Hawkins, E., Inorg. Chem., (2010), 49: 4843-4853.

13. Tan, L., Shen, J., Liu, J., Zeng, L., Jin- L. and Weng, C., Dalton Trans, (2012), 41: 4575-4587.

14. Xiong, Y. and Ji, L.N., Coord, Chem. Rev., (1999), 185: 711-733.

15. Thanasekaran, P., Rajendran, T., Rajagopal, S., Srinivasan, C., Ramaraj, R., Ramamurthy, P., Venkatachalapathy, B., J. Phys. Chem. A, (1997), 101: 8195-8199.

16. Saha, B., Stanbury, D.M., Inorg. Chem., (2000) 39:1294-1300.

17. Connors, K.A., Binding Constants: The Measurement of Stability, John Wiley \& Sons, Ltd, Chichester, U.K., (1987).

18. Kalyanasundaram, K., Photochemistry of Polypyridine and porphyrin complexes,Academic Press,London,(1992).

19. Sheeba Daniel, Allen Gnana Raj, G., Green Chemistry and Technology Letters,1(1),(2015),77-81. 